\title{
HLA Mismatch
}

National Cancer Institute

\section{Source}

National Cancer Institute. HLA Mismatch. NCI Thesaurus. Code C126298.

The state when a recipient of a hematopoietic stem cell transplant is not fully matched with their donor for HLA-A, HLA-B, HLA-C, and HLA-DRB1. 